\title{
Beïda Chikhi (dir.), Destinées voyageuses. La Patrie, la France, le Monde
}

Ilaria Vitali

\section{(2) OpenEdition}

1 Journals

\section{Edizione digitale}

URL: http://journals.openedition.org/studifrancesi/9048

DOI: $10.4000 /$ studifrancesi.9048

ISSN: 2421-5856

\section{Editore}

Rosenberg \& Sellier

\section{Edizione cartacea}

Data di pubblicazione: 1 octobre 2008

Paginazione: 494-495

ISSN: 0039-2944

\section{Notizia bibliografica digitale}

Ilaria Vitali, «Beïda Chikhi (dir.), Destinées voyageuses. La Patrie, la France, le Monde», Studi Francesi

[Online], 155 (LII | II) | 2008, online dal 30 novembre 2015, consultato il 08 janvier 2021. URL: http:// journals.openedition.org/studifrancesi/9048 ; DOI: https://doi.org/10.4000/studifrancesi.9048

Questo documento è stato generato automaticamente il 8 janvier 2021.

\section{(c) (†) $\ominus$}

Studi Francesi è distribuita con Licenza Creative Commons Attribuzione - Non commerciale - Non opere derivate 4.0 Internazionale. 


\title{
Beïda Chikhi (dir.), Destinées voyageuses. La Patrie, la France, le Monde
}

\author{
Ilaria Vitali
}

\section{NOTIZIA}

BË̈DA CHIKHI (dir.), Destinées voyageuses. La Patrie, la France, le Monde, Paris, Presses Universitaires de Paris Sorbonne, 2006 («Lettres Francophones»), pp. 262.

1 Partenze, traversate, migrazioni, erranze, esili: ecco le tappe del viaggio nella geografia delle «littératures francophones du voyage» che propone questo volume. Un saggio di grande interesse, che raccoglie gli atti del Colloque International Destinées voyageuses des littératures francophones, tenutosi nel 2002 presso l'Université Strasbourg II, in collaborazione con il Centre International d'Etudes Francophones dell'Université Paris IV-Sorbonne.

2 Gli studi raccolti in questo volume dalla curatrice, Beïda CHIKHI, si propongono di analizzare quelle singolari voci francofone, tiraillées tra la patria, il pays d'accueil e l'erranza. Un triangolo emblematico che appare nell'eloquente sottotitolo di questo studio: «la Patrie, la France, le monde». Un triangolo, come sottolinea Beïda Chikhi, deformato dalle metamorfosi e dalle anamorfosi, ma che resta pur sempre riconoscibile nel percorso individuale degli scrittori. La patria rappresenta il luogo del patrimonio primigenio e della sua trasmissione; la Francia costituisce la consacrazione letteraria; il mondo è lo spazio da conquistare attraverso lo slancio narrativo e la riflessione sul sé e sulla contemporaneità. La tensione linguistica e letteraria, a metà tra il destino e la necessità, la volontà e il piacere, si esplica nell'esaltazione della poétique-carrefour, che conferisce all'autore francofono un'identità di passeur per eccellenza. Mai come oggi, il movimento migratorio è stato così denso e complesso, capace di generare uno spazio letterario di migrance da indagare con strumenti specifici, che non lasciano spazio 
all'esotismo: «Les écrivains francophones se détournent en général des auteurs qui ont gavé la littérature française de récits exotiques et de clichés» (p. 8).

Strutturato in quattro parti, il volume definisce alcuni aspetti fondamentali di questa poetica del viaggio. La prima sezione, «L'Europe et son ailleurs», s'interroga sul concetto di alterità inteso da un punto di vista europeo. L'intervento di apertura di Tania MANCA sull'esploratore e viaggiatore François Le Vaillant, mostra come nel XVIII secolo si delineino già $\mathrm{i}$ tratti del viaggio inteso come operazione intellettuale di distacco, riflessione e scoperta dell'altro; il secondo articolo, di Marc QUAGHEBEUR, affronta «l'étrange hantise des écrivains belges», la relazione ambigua nei confronti della Francia che caratterizza gli scrittori belgi anche nel campo della letteratura di viaggio; il terzo intervento, di Jean-François GUENNoc, si articola infine sull'opera di Nicolas Bouvier e sulla sua reinvenzione dell'imago mundi. La seconda parte si distacca dall'Europa per attraccare in Algeria e nelle Antille. Sono qui analizzati il percorso di Édouard Glissant e la sua «divination du monde», tra finzione letteraria ed elaborazione teorica (Brigitte DoDu); la scrittura della «transumanza» nell'opera di Assia Djebar (Karin HolTER); il mito della rinascita nel romanzo N'zid dell'autrice algerina Malika Mokeddem (Anne-Marie NAHLOVSKI); e infine l'opera di Slimane Benaïssa, romanziere e uomo di teatro, nell'articolo di Roseline BAFFET. Nella terza sezione, dal titolo «Migrances, exils, utopies», esilio e utopia si uniscono per interrogare l'identità e lo spazio. Compongono questa sezione diversi studi su alcune singularités francophones: un intervento di Alexis VASTCHENKO sul cileno Vicente Huidobro; uno studio comparato sulla funzione utopica della neutralità nell'esilio nell'opera di Eduardo Manet, François Cheng e Andreï Makine (Dorothée HIVER); un interessante articolo sulle «migrations intimes» secondo la beur Farida Belghoul (Caroline EYSEL); e, in conclusione, un saggio sulla letteratura migrante dedicata ai ragazzi, a cura di Anne SCHNEIDER. La quarta ed ultima parte di questo volume trasmette in presa diretta la parola degli autori invitati alla tavola rotonda. Il lettore potrà qui apprezzare gli interventi di Claude BEAUSOLEIL, Nabile Farès, Tierno Monenembo, Marc QUaGHebeuR, Nouredine SAAdI, esempi perfetti di quelle «destinées voyageuses», capaci di forgiare nuove poetiche e di creare concetti letterari originali.

Un saggio per sfatare l'opinione comune che l'esilio sia esclusivamente luogo doloroso, per sdrammatizzarlo ed analizzarne a fondo le mille sfaccettature, compreso lo stimolo creativo che il distacco dal paese natale può portare con sé. Un inno alla «navigation littéraire», alla conoscenza del vicino e del lontano, alla scoperta del simile e del diverso, attraverso $\mathrm{i}$ destini erranti di alcuni tra $\mathrm{i}$ maggiori autori francofoni contemporanei. 